Alcides Greca (1889-1956), un hombre de letras y un hombre de estudio. Apuntes para la construcción de una biografía escrituraria

\title{
Alcides Greca (1889-1956), un hombre de letras y un hombre de estudio. Apuntes para la construcción de una biografía escrituraria
}

\section{Alcides Greca (1889-1956), a man of letters, a literate man. Notes to build a biography of writing}

\author{
María Florencia Antequera \\ Universidad Católica Argentina, \\ Universidad Nacional Rosario; \\ IH- Instituto de estudios Históricos, Económicos, Sociales e Internacionales; \\ Consejo Nacional de Investigaciones Científicas y Técnicas (Argentina) \\ mfantequera@hotmail.com
}

\section{Resumen}

En este artículo, intentamos reconstruir una semblanza biográfica del multifacético intelectual santafesino Alcides Greca (1889-1956). De este modo, a partir de sus textos éditos e inéditos, sus derroteros por la universidad, su frondosa actividad escrituraria, su pionera incursión en el cine y sus inquietudes sobre urbanismo, derecho y política, revisitamos su legado como hombre de letras y como hombre de estudio.

Palabras clave

Alcides Greca; biografía escrituraria; hombre de letras.

\begin{abstract}
In this article we attempt to rebuild a biographical sketch of the multifaceted intellectual from the province of Santa Fe Alcides Greca (1889-1956). Thus, taking into account his published and unpublished texts, his way along the university, his dense writing activity, his pioneer filmmaker incursion and his interest in urbanism, law and politics, we revisit his legacy as a man of letters and as a literate man.
\end{abstract}

\section{Keywords}

Alcides Greca; biography of writing; man of letters. 


\section{María Florencia Antequera}

\section{Presentación}

La pertinencia de una comunicación dedicada a las coordenadas biográficas del intelectual sanjavierino Alcides Greca está suscitada por el deseo de darle mayor visibilidad al legado de un escritor que, por fuera de los circuitos santafesinos, resulta escasamente conocido. En este sentido, nos interesa poner en circulación estos elementos que cotejamos con materiales provenientes de la colección documental A. Greca y con documentos internos, suministrados por la Universidad Nacional del Litoral. De este modo, bregamos por enumerar el amplio listado de sus obras publicadas -literarias, sobre urbanismo, sobre temas relativos a la cuestión universitaria, etc.- y describimos algunas de ellas así como también repasamos sus textos inéditos. Relevamos, de igual modo, algunas notas de su producción cinematográfica y cartografiamos los lineamientos centrales de sus intervenciones en urbanismo y en ciencias jurídicas.

Aguijoneados por estas inquietudes, intentamos establecer una semblanza biográfica que apunte a resignificar sus aportes, atendiendo a las múltiples facetas que lo definían -hombre de letras, hombre de estudio, comprometido docente universitario, pionero cineasta, militante político- y que no deben pensarse desgajadas unas de otras, sino conformando una abigarrada trayectoria. Para tal fin, apuntamos una descripción pormenorizada de su trayectoria intelectual atendiendo a su capital cultural y a su reconocimiento social (Ferrary, 1999).

\section{Un Quijote litoraleño de las letras}

Alcides Gregorio Greca, hijo de los inmigrantes Francisco Greca y Magdalena Trucco $^{1}$, nació el 13 de febrero de 1889 en San Javier, pequeña localidad a $140 \mathrm{~km}$ de Santa Fe. El segundo de doce hermanos fue escritor, cineasta, viajero, jurisconsulto, docente universitario, periodista y militante político ${ }^{2}$. La variedad de oficios se amalgama en un fortísimo deseo que espoleó su labor: ser un hombre de letras (Goloboff, 2014), quizás su máxima aspiración. Las coordenadas de su itinerario intelectual estuvieron jalonadas por tres inquietudes que se entrelazaron a lo largo de su vida -la universidad, el urbanismo y la literatura-, aunque también sobresalió por la representación parlamentaria, dentro de las filas del radicalismo3: fue diputado provincial (1912-1916) y senador provincial (1920-1923) así como convencional constituyente entre 1920 y 1921 y diputado nacional entre 1926 y 1930, hasta el golpe de Uriburu. De este modo, la riqueza de su mirada se sustenta entre otros aspectos- en su pertenencia a la clase política santafesina, pero su

\footnotetext{
${ }^{1}$ De origen italiano, su padre y francés, su madre.

2 Esta comunicación retoma aspectos de nuestra tesis doctoral titulada El relato de viajes en la obra de Alcides Greca como formación de una subjetividad moderna en el campo intelectual argentino.

${ }^{3}$ Consideramos que sopesar sus proyectos presentados, calibrar los debates que libró y evaluar cómo se desenvolvió hacia el interior del radicalismo son ítems que ameritan un estudio ulterior profundo.
} 


\section{Alcides Greca (1889-1956), un hombre de letras y un hombre de estudio. Apuntes para la construcción de una biografía escrituraria}

inclusión en el registro literario, la legitimación de su acceso y sus usos de la lengua -o su reconocimiento literario- son también temas complejos para resolver. En efecto, para un intelectual que vivió la mayor parte de su tiempo en una ciudad del interior, Rosario, y no en la gran capital, el circuito de reconocimiento debe legitimarse en otros carriles: "mi manera de producir en literatura no es común entre los hombres de letras, entre los cuales aspiro a figurar algunas vez" (Greca, 1929 , p. 5). Esta aspiración se fue consumando paulatinamente: son sus libros los que dan cuenta de este anhelo. Pero, ¿en qué consistía esta pretensión para Greca? Podríamos aducir que se es hombre de letras cuando se tiene una actividad escrituraria de cierta consagración, vinculada -claro está- a los pares, es decir, cuando esos nodos de productividad intelectual se cofunden con los entramados de notoriedad en relación a los contemporáneos. Es necesario apuntar entonces que la visibilidad en ciertas condiciones de producción (Cattaruzza y Eujanian, 2003), las cuales establecen un contexto concreto con sus circunstancias específicas de producción, apropiación y circulación de los bienes, se resignifican en un horizonte de expectativa: al paso del deseo, el afán por escribir y publicar, y también por la repercusión y circulación de sus libros, estuvieron presentes en su itinerario intelectual, desde sus comienzos. La escritura se entronca de este modo con ese deseo que motivaba el dar a conocer su producción, hacer circular sus escritos y darlos a publicidad, cimentando así su figura de escritor (Gramuglio, 1992).

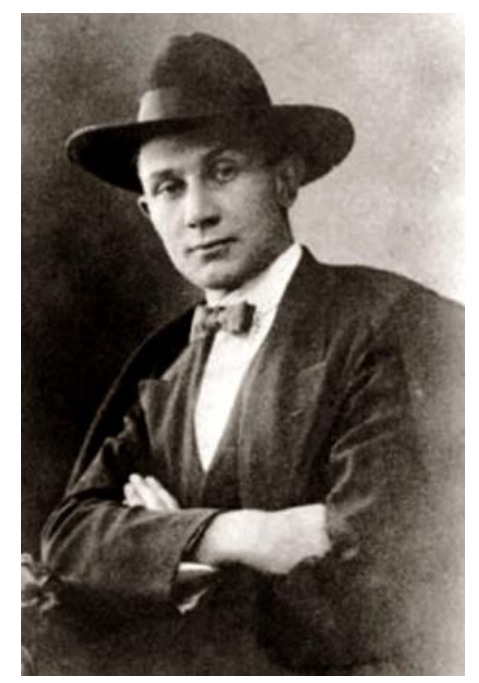

Fig. 1 Alcides Greca, con sombrero.

En rigor, siendo muy joven, su carrera literaria se inauguró en 1909 con la publicación de Palabras de pelea, Sinfonía del cielo (himnos en prosa) y Lágrimas negras, estos últimos de 1910. En 1915 escribe Laureles del pantano, un informe de su labor parlamentaria, que incluye crónicas y discursos. En 1927, publicó su novela 
Viento norte. En 1931 editó Cuentos del Comitét, un compilado de corrosivos relatos basados en anécdotas humorísticas que no hacen sino denunciar el fraude electoral, los vicios y las trapisondas de la clase política santafesina. Detentan un marcado cariz autobiográfico, pues las anécdotas fueron recogidas entre 1912 y 1930, es decir, desde los comienzos de su labor política partidaria hasta el golpe de Uriburu. En efecto, "la quiebra del orden constitucional en el año treinta le impone la necesidad de una personal revisión cuyo somero análisis aflora en estos relatos" (Santa Cruz, 1981, p. 13). Al revisitar un pasado cercano y vivido en primera persona, en este libro Greca no solo le da al significante cuento un doble y dinámico espesor: como relato y, paralelamente, como impostura sino que también permite vislumbrar, en el intersticio, las elecciones provinciales de 1928 y el golpe de 1930, donde, por ejemplo, el protagonista del relato "Un experimento" es casi un exiliado en su propia ciudad.

Además de artículos y reseñas bibliográficas para la revista Universidad de la UNL y otras intervenciones en medios gráficos, en 1936 publicó en la editorial Ercilla de Santiago de Chile quizás su novela más conocida La pampa gringa, bautizada como "novela del sur santafesino" en contraposición con Viento norte, "novela del norte santafesino".

Por su parte, en 1941 los ensayos En torno al hombre fueron editados por Losada, en la colección Azul y blanco ${ }^{5}$. El volumen contiene diez textos que giran en torno a variopintos temas: el complejo de inferioridad, la intimidad, lo femenino, la chismografía, etc. Forma parte de este volumen un curioso escrito titulado "Psicoanálisis del hombre con sombrero", el cual contiene singulares disquisiciones sobre los sombreros y los estados espirituales de los sujetos que los portan ya que: "las aspiraciones o mejor dicho las debilidades de una persona, pueden juzgarse por los adornos que carga encima", según Greca (1941, p. 54). "Al hablar de la psicología del sombrero -sostiene- no pretendemos dotar de alma a un objeto inanimado, como suele hacerse en ciertas fantasías literarias. Trataremos solo de que los sombreros nos hablen de las cabezas que llevan dentro" (Greca, 1941, p. 55).

Ahora bien, a través de este elemento de uso personal, y siguiendo su razonamiento, podemos aventurar quizás la imagen con la que Alcides Greca deseaba ingresar en el archivo visual de sus lectores futuros. Un retrato fotográfico, una fotografía de estudio, aquella que mayor divulgación tuvo, lo encuentra con un sombrero de copa, de mediana ala, forrado, que resalta su porte varonil y elegante. Levanta la vista, esgrime una mirada fija y posa con aires de seguridad, cruzado de brazos. Viste un traje oscuro, camisa blanca, un moño y una capa (Fig. 1). Es esta quizás su vestimenta de trabajo, como docente en la UNL, como parlamentario, como jurisconsulto. Su

\footnotetext{
${ }^{4}$ Este último es el único de sus libros que se reeditó en los últimos años, el emprendimiento fue llevado a cabo por el Diario La Capital de Rosario.

${ }^{5}$ Esta colección está conformada por los siguientes títulos: Un titán de los Andes de Ricardo Rojas (es decir, el interesantísimo Ollantay de Rojas); Seis figuras del plata de Juan Pablo Echagüe; Buenos Aires (Imágenes y semblanzas) de Álvaro Melián Lafinur; Temas existenciales de Homero Guglielmini; Estudios en tres literaturas de Rafael Alberto Arrieta; Alma de América de Ramón Vásquez.
} 


\section{Alcides Greca (1889-1956), un hombre de letras y un hombre de estudio. Apuntes para la construcción de una biografía escrituraria}

delgadez lo asimila, al decir del arquitecto y amigo Ángel Guido, a un Quijote litoraleño.

Retomando sus publicaciones, sin lugar a dudas es La torre de los ingleses (1929), crónicas de viajes, su libro más original por la mirada performativa con que imprime los sitios por los cuales pasea (Antequera, 2018; 2019). Solo nos interesa destacar un rasgo sugestivo de este texto: consta de un apartado final denominado "Juicios sobre Viento norte" en donde Greca recopila opiniones de personalidades extranjeras y locales sobre su anterior novela (la cual data de 1927 pero que bajo los impulsos de Elías Castelnuovo y el sello de Claridad se volvió a editar en 1938). El espectro internacional de personalidades citadas en este elemento paratextual abarca a Manoel Gahisto de la Revue de l'Amerique Latine (París)'; Rufino Blanco Bombona (Madrid), Emilio De Matteis (Génova)7; y en el plano nacional, podemos destacar los pareceres de los escritores Ricardo Rojas, Benito Lynch, Roberto Mariani, Arturo Capdevila y Elías Castelnuovo ${ }^{8}$. También rescata los pareceres del historiador Juan Álvarez y del jurisconsulto Rafael Bielsa, entre otros. De igual modo, se consignan las opiniones vertidas por la prensa nacional de casi todos los medios gráficos importantes del período, así como de medios gráficos rosarinos y de las ciudades de Santa Fe y Gálvez. A nuestro entender, estas funcionan como una búsqueda de legitimación y como una instancia de autoafirmación ya que un comentario encomiástico, una dedicatoria, unas líneas en algún periódico, o mejor, un prólogo, contribuían a catapultar a un escritor.

Esta operación de divulgar qué dijeron otros escritores -prestigiosos y con cierta repercusión- (maniobra que llamaríamos vulgarmente en la actualidad autobombo) se repitió asimismo al publicar La torre...: aunque en dicha ocasión, los instrumentos fueron los medios gráficos. De este modo, en diversas publicaciones de amplia circulación de la década del veinte, Greca dio a conocer las opiniones vertidas por sus colegas, hasta el punto de divulgar en el diario La Capital una carta personal que le enviara el prestigioso escritor Miguel de Unamuno, rector de Salamanca, ponderando positivamente La torre... (Antequera, 2017). Es esta una jugada publicitaria, de autoafirmación y de legitimación, una apuesta de alto impacto en el contexto de producción. Pero por cierto no es la única vez en que incurre en estas lides. En una entrevista publicada el 24 de julio de 1929, frente a la pregunta del periódico Democracia sobre su vocación profesional, Greca relata:

Yo no debí ser político sino escritor. Desgraciadamente la política me tomó demasiado joven. Fui diputado cuando acababa de cumplir veintidós años. Pero tampoco hay que lamentarse mucho. La política ha salvado al mundo de unos cuantos malos libros míos, y me ha permitido escribir en plena madurez. Estoy en el máximo de mi potencia psíquica.

\footnotetext{
${ }^{6}$ Su opinión aparece en La torre... en el idioma original, en francés.

7 Sus líneas son recopiladas en italiano.

8 Con quien, por cierto, sostiene un interesante intercambio epistolar, que hemos analizado. Ver Antequera, 2018.
} 
La cristalización de su figura pública, como vemos, fue un proceso lento de maduración, hecho de tentativas, repliegues, dilaciones y, cuando se presentaba alguna ocasión oportuna como la anteriormente expuesta, pasos adelante. Esta singular entrevista contiene fotografías del escritor y de su familia: su esposa, Rosa Pierri y su pequeño hijo Alcibíades Alejandro, quien nació el 2 de abril de 1921. Las preguntas realizadas reclaman sus dictámenes sobre sucesos de la actualidad política de su tiempo pero, por sobre todas las cosas, sobre su vida privada. Con motivo de dar a conocer su reciente libro, Greca fue entrevistado en su propia casa junto a sus íntimos: entendemos que Greca intercambia publicidad de su vida privada por publicidad de su último libro.

Como hijo de inmigrante y como intelectual del interior, en este sentido, la función pública -senador, diputado, convencional constituyente y cabe agregar también, docente universitario- viene a reforzar ese rol de legitimación que además está dado por su labor de periodista, actividad que realizó desde los 18 años. Fue mentor de diversos medios de comunicación desde su estadía en La Plata como estudiante universitario. Ciertamente, fundó y dirigió en San Javier los periódicos El Mocoví (1907) y La pura verdad (1911). El perfil de este último estaba contenido en la publicidad que anunciaba su aparición en el mercado:

[...] traerá una abundante información política, caricaturas de actualidad, comentarios sabrosos, notas sociales, impresiones de arte y pocos, muy pocos chismes. Defenderá las buenas causas, fustigará a los engreídos nepotes, denunciará los robos y no callará los crímenes y los fraudes. Intimidades de la vida privada no aparecerán en sus columnas (s/d).

La Universidad Nacional de La Plata fue la institución donde cursó su carrera: allí se recibió de abogado en 1916. En esa ciudad publicó con veintitrés años un panfleto titulado Lepra (Panfleto de combate) (1912), cuya tapa contiene la frase del incansable polemista y periodista francoespañol Luis Bonafoux: "Yo soy yo. No lo que los otros quieren que sea". En una suerte de enrolarse en el linaje de los contestatarios, sostuvo desde las páginas de Lepra una posición de enfrentamiento en relación al clericalismo (que lo acompañaría siempre) y una fuerte aversión a la corrupción del periodismo. En este período de juventud se encontraba más ligado ideológicamente al socialismo (Santa Cruz, 1981). Los tópicos de Lepra son la vida en Santa Fe -que define como ciudad conventual en donde se siente como factor eficiente de progreso-, su incipiente participación política partidaria y su rol como intelectual:

Pensar con libertad, sin que dogmas de ninguna clase perturben mi cabeza, defender las buenas causas, ser como Quijote, partidario de los débiles, los pobres, los desamparados, desear para el pueblo una instrucción vasta y libre, exigir franqueza y honradez en los amigos y energía y rectitud en los gobiernos. He ahí mis crímenes (1912, p. 9). 


\section{Alcides Greca (1889-1956), un hombre de letras y un hombre de estudio. Apuntes para la construcción de una biografía escrituraria}

Este pequeño opúsculo contiene asimismo cartas ya publicadas en algunos medios gráficos y diversas exhortaciones al lector. Resulta interesante que en la contratapa del texto, Greca incluyera un listado de obras en preparación, denominadas "panfletos", conteniendo los siguientes títulos: El sacristán y su escudero, Apoteosis del sacristán, Las cloacas máximas del periodismo. Finalmente, estas obras, que se anunciaban por la sola lectura de sus títulos como polémicas, no se escribieron (o quizás se perdieron): el escritor no vuelve a hacer mención a las mismas. Algo similar aconteció con Rivadavia socialista. Estudio crítico de las leyes agrarias de los años 1922 y 1826 y Breviario de belleza, amor y verdad, aunque este último fue publicado fragmentariamente en Sinfonía del cielo y Lágrimas negras.

Por otra parte, Greca instituyó el periódico El paladín del norte (1914). En 1915 en Santa Fe, fundó el diario La Palabra, antecedente directo del actual El Litoral, en donde trabajó junto a Alejandro Grüning Rosas, Salvador Caputto, Luis Bonaparte, Horacio Varela, Pablo Vrillaud, entre otros militantes radicales y reformistas. Este era un diario radical, que campeaba entre lo literario y lo político. Fue asiduo colaborador en varios medios gráficos entre los cuales destacamos La Capital de Rosario. Entendemos que la vigorosa actividad periodística de Greca no ha sido todavía suficientemente aquilatada: aguarda un estudio detallado en torno a sus contribuciones en la prensa escrita, sus diatribas en torno a las características éticas y morales del periodista así como también a su voluntad fundadora de diversos medios gráficos, sumamente notable ya que fueron varios los medios por él erigidos.

\section{Construcción identitaria}

La construcción identitaria del sujeto escritural se forma, de hecho, a partir de fisuras y superposiciones de funciones en el espacio social, de acuerdo a dos principios de diferenciación: el capital cultural (entendido como la variable educativa) y el capital económico, como señala Bourdieu (2008, p. 69). Greca expone en estos términos su lectura sobre la inserción en el campo intelectual: "la verdadera élite no se amasa en la familia, como algunos creen, ni se adquiere con la aparatosidad de modelos y vestidos. La verdadera, la que no falla nunca, es solo producto de una gran cultura" (Greca, 1929, p. 24). Por un lado, Greca representa el acceso a los bienes culturales de la primera generación de hijos de inmigrantes llegados a la Argentina a fines del siglo XIX en el marco de un diseño de país que contaba con mecanismos de integración de los inmigrantes al tejido social. Por ende, su origen debe legitimarse en el campo intelectual ya que no se sustentaba ni en la portación de un apellido ilustre ni en una fortuna. En efecto, como podemos apreciar Greca era totalmente consciente de que debía legitimarse y que ese espacio de legitimación era "la cultura".

En este sentido, cabría proponer tres núcleos que Greca transitó y que posibilitaron la emergencia de su singular obra: uno, ligado a los artistas e intelectuales de Rosario, más precisamente en torno a los hermanos Guido (Antequera, 2019); otro, 
relacionado con la UNL en estrecha cercanía con la denominada Escuela del Litoral cuyo centro era Rafael Bielsa y el tercero en vinculación con la UCR. En relación con este último, podemos agregar que el proceso político que acompañó el nacimiento del Partido Radical, lo tuvo a Greca como uno de sus protagonistas (Persello, 2007; Macor, 2010). Con el golpe de Uriburu, fue arrestado en dos oportunidades junto con otros militantes correligionarios como queda sucintamente descripto en $\mathrm{La}$ torre... Privado de su libertad durante varios meses en la isla Martín García por su yrigoyenismo, trasmuta esas experiencias en un pequeño libro, Tras los alambrados de Martín García (1934), donde recoge y eslabona sus vivencias del encierro, aunque sin describir los tormentos sufridos.

Fue la UCR el horizonte político partidario en el que se inscribió durante toda su vida. A raíz del acceso de los sectores medios a la participación política y social, intelectuales como Greca encontraron cabida en este partido y se constituyeron como parlamentarios y profesionales liberales que producían literatura y no a la inversa, si nos posicionamos desde el punto de vista de lo remunerativo. Greca emergería entonces formando parte de la fracción de la pequeña burguesía letrada que encuentra en su paso por la universidad el ansiado ascenso social o, en términos más amplios, en la cultura su peldaño para legitimar su lugar.

\section{Incursión en el cine}

Los intereses intelectuales de Greca desde su juventud tuvieron en cuenta las injusticias sociales: se sentía vitalmente comprometido frente a las iniquidades del proceso inmigratorio -que de manera significativa representa su novela La pampa gringa- o sobre las comunidades indígenas, en especial sobre los postergados mocovíes, comunidad a la que estaba unido también por un fuerte lazo de afecto, como se puede vislumbrar en la novela Viento norte, el film El último malón (1917) y la obra de teatro inédita Ananoc. Tragedia de la raza nativa (En 5 actos y 7 cuadros $)^{9}$ de 1945. En su infancia, transcurrida en San Javier, viejo poblado colonial de fronteras del norte de la provincia, creció en contacto con estos indígenas (Greca, 1929). Este interés por los mocovíes fue retomado también, aunque de modo espasmódico y tangencial, en La torre... Como vemos, en diversos registros y con variaciones de intensidad, focalización y trama, Greca fue trabajando esta temática que migró en diferentes registros a lo largo de su vida (Antequera, 2018).

Este hito dentro de la historia santafesina, la rebelión mocoví, representado por Greca en su film, se vincula con una problemática de mayor envergadura: el sometimiento de las comunidades indígenas y la expropiación de sus tierras. Ninguneo, marginación y expolio podrían ser los términos en que se sometió a la población indígena de San Javier. Trece años más tarde de acontecida la rebelión, en el año 1917, Greca filma una recreación de los sucesos de 1904: El último malón es

\footnotetext{
${ }^{9}$ Esta obra inédita fue digitalizada por Verónica y Daniela Greca, bisnietas del escritor, con nuestra colaboración. Amerita un estudio crítico literario y lingüístico ya que brega por imitar el habla indígena, intentando profundizar la verosimilitud y el verismo del relato.
} 


\section{Alcides Greca (1889-1956), un hombre de letras y un hombre de estudio. Apuntes para la construcción de una biografía escrituraria}

uno de los primeros largometrajes argentinos en $35 \mathrm{~mm}$ y el más antiguo del interior del país. Este documento fílmico, que se conserva en la actualidad ${ }^{10}$, es revisitado por la crítica cinematográfica, entre otros motivos, por contar con la participación de quienes en 1904 habían protagonizado en San Javier la rebelión mocoví. En efecto, los participantes fueron los propios protagonistas del levantamiento: por ejemplo, el cacique mocoví Mariano López, líder del levantamiento. Solamente el papel del cacique rebelde Jesús Salvador y de su compañera de andanzas Rosa Paiquí fueron interpretados por los dos únicos actores profesionales del elenco, provenientes del ámbito teatral. El personaje femenino estuvo a cargo de la actriz Rosa Volpe. El resto de los colaboradores fueron los indios lugareños, la paisanada local y los familiares y amigos del mismo Greca ${ }^{11}$. Esta película silente, a caballo entre lo documental y lo ficcional, cuenta con una particular visión de la rebelión mocoví y fue filmada en locaciones del mismo San Javier. El estreno tuvo lugar el 4 de abril de 1918 en el Palace Theatre de Rosario y fue el único film de Greca ya que no volvió a incursionar en este arte. Él mismo fue quien la financió, mediante el amparo de lo que dio en llamar la Greca Films, cuya dirección coincidía con su estudio jurídico: Av. Pellegrini 1655 (Rosario). El ya citado Ángel Guido elaboró los carteles introductorios cuya estética podría caracterizarse como tributaria del art nouveau, contrastando con el resto del film.

En uno de los primigenios estudios críticos que lee en paralelo el texto literario Viento norte y la producción cinematográfica de Greca, el crítico argentino Eduardo Romano (1991, p. 8) apunta que cabe pensar que, preocupado por la actualidad y el destino de los indígenas, Greca haya querido mostrar su situación para movilizar la opinión pública. Sin ánimo de realizar un análisis detallado del film, solo avanzaremos en destacar que, de alguna forma, El último malón constituye un entrecruzamiento de dos planos perfectamente diferenciables que hasta casi se repelen, podríamos decir: una historia amorosa de corte folletinesco junto a otra documental en torno a la rebelión de los mocovíes (Romano, 1991). Quizás Greca, siempre atento a las repercusiones de su obra, pensó que la historia de amor folletinesca le garantizaría al film cierta cantidad de público y de este modo, la anhelada resonancia mediática. Sin embargo, podemos advertir un fuerte componente de política partidaria santafesina propia del momento de enunciación que está también presente ${ }^{12}$.

\footnotetext{
${ }^{10}$ Fue Fernando Birri, en los sesenta, quien sacó a este film del ostracismo en que había caído. Vale decir que también contribuyó la propia familia Greca y el Cine Club Rosario, fundamentalmente en la figura de Fernando Vigévano, quien bregó por recuperar técnicamente la pieza en 1967 y realizó una nueva copia que, por el deterioro del tiempo, quedó con una duración de 58 minutos, diferente -por cierto- a los 85 minutos de la pieza original. La película fue coloreada por tramos. La presentación, el epílogo y cada capítulo estaban virados a un color distinto (verde, sepia, rojo, etc.). En su traspaso a $16 \mathrm{~mm}$ se dejó en blanco y negro. En la actualidad entendemos que erigió en un film de culto.

$11 \mathrm{http}: / /$ www.pampagringa.com.ar/BIOGRAFIAS/Greca_Alcides/ultimo_malon.htm

${ }^{12}$ Algunos críticos sostienen que en 1924 hubo una reescritura por parte de Greca de los carteles que introducen las escenas, por motivaciones de índole política.
} 
Las miradas antropológicas también se cruzan y, de hecho, entran en fragrantes tensiones: los roles del blanco, del indígena, de la comunidad, así como de la clase política y los caciques indígenas no son lineales sino que presentan pliegues y fluctuaciones. Uno de los primeros carteles, que funciona casi como un prólogo, expresa: "No será la poesía enfermiza de boulevard importada de París, ni el folletín policial, ni el novelón por entregas. Será la historia de una raza americana y heroica". En rigor, El último malón expone las tensiones civilización/barbarie, en varias direcciones: por ejemplo, se puede advertir una oscilación o vaivén entre una posición "civilizadora" y otra de denuncia de la situación de los mocovíes. Asimismo, están presentes sincréticamente elementos religiosos y culturales de vertientes que en principio parecieran inconciliables. También tiene lugar la tensión irresoluta entre lenguajes cinematográfico y literario, planteando por momentos ciertos forzamientos en la historia: recordemos que este film luego será una trasposición hacia la novela Viento norte. Estas características -entre otras- hacen de la incursión cinematográfica de Greca una pieza muy destacable e interesante para su estudio (Greca D, 2014; Greca V, 2008; 2009; 2013) ${ }^{13}$.

\section{Un hombre de estudio: la universidad como espacio de legitimación}

La pertenencia a alguna de las pocas instituciones universitarias que tenían lugar en el momento en que Greca cursó sus estudios: Univ. de Bs. As., Univ. Nac. de La Plata, Univ. Nac. de Córdoba, Univ. Nac. del Litoral o Univ. Nac. de Tucumán, se constituía en objetivo, meta y objeto de deseo para las clases medias (Cfr. Chiroleu, 2000, p. 362), plasmándose en la creciente irrupción en los claustros de los sectores sociales en ascenso producto de la inmigración. A este propósito, entendemos que Greca es un "hijo legítimo de la Reforma del 18", sin la cual no hubiera podido acceder a este nivel educativo de tanto peso simbólico y propiciador de acceso económico (Cfr. Macor y Piazzesi 2010; Piazzesi y Bacolla 2014; Macor y Tcatch 2003). La UNL fue entonces otro de los espacios en donde Greca se desenvolvió y buscó su legitimación. En realidad, nos referimos específicamente a ciertos núcleos de esta universidad ligados al derecho administrativo y, dentro de este, al derecho municipal y sus espacios concomitantes, por ejemplo, el Instituto de investigaciones jurídicopolíticas o la dirección de la Revista de la Fac. de Derecho. El 26 de junio de 1920 comenzó sus funciones como profesor titular del espacio curricular "Derecho administrativo" en la Fac. de Cs. Jurídicas y Sociales, según puede constatarse en su legajo académico (n⿳0 748, foja 4) ${ }^{14}$. Análogamente, Greca se desempeñó como

\footnotetext{
${ }^{13}$ Mucho más se podría decir de la película. Citamos solamente algunos como referencia; Tompkins, C. (2014). El último malón de Alcides Greca. Repetición y cine de atracciones. Studies in Latin American Popular Culture, 32, 2014, pp. 97-119; Rodríguez, A. (2008) La trama, la historia y la política en El último malón. Polhis, 8. Benzi, M (2018) La mirada etnográfica de A. Greca en El último malón, Culturas (12). Destacamos los valiosos trabajos de Verónica y Daniela Greca.

${ }^{14}$ Agradecemos especialmente al equipo de trabajo del Museo Histórico de la UNL. Los datos precisos de su desempeño académico en la Universidad Nacional del Litoral los tomamos de su Legajo académico (n-0 748).
} 


\section{Alcides Greca (1889-1956), un hombre de letras y un hombre de estudio. Apuntes para la construcción de una biografía escrituraria}

profesor de "Derecho municipal comparado" desde 1931, con el formato de curso libre (Exp. G. 171/931) en sus comienzos y luego con una inserción curricular más estable, como asignatura obligatoria.

Greca se constituyó en abanderado de la defensa de la cátedra de "Derecho municipal" y luego, en acérrimo celador de su autonomía científica ${ }^{15}$. Dicha cátedra había sido fundada en la UNL en 1921, corriendo el riesgo de desaparecer en 1944. El sanjavierino sostuvo la defensa de la misma desde la Revista de Derecho y Administración Municipal (núm. 173) exponiendo sus conceptos sobre la naturaleza del derecho municipal como capítulo especializado del derecho administrativo (Hernández, 2003, p. 7) ${ }^{16}$. Otro punto digno de acentuar es que Greca se desempeñó como profesor adjunto de Bielsa en la cátedra de "Derecho Administrativo". Greca y Bielsa se conocían casi desde el momento en que se fundara la UNL y desde la formación del plantel de profesores.

A raíz de su prestigio profesional, en múltiples oportunidades fue convocado a proferir palabras de homenaje frente a auditorios diversos. La vivacidad de sus performances oratorias lo convirtió en un gran comunicador y conferencista (Antequera, 2017). Dentro de un marcado interés por los problemas de la universidad, escribió varios ensayos, entre ellos uno titulado "La Reforma universitaria. Su significado político y social", que pronunció el 15 de junio de 1938 en el anfiteatro de la Fac. de Medicina con motivo del XX aniversario de la Reforma y que editó el Centro de Estudiantes de Derecho, filial Rosario. También se destaca: "Tragedia espiritual para los argentinos que hoy tienen veinte años", discurso de apertura del año académico en 1941, pronunciado en el Paraninfo de la UNL.

Podemos recapitular entonces que si la propiedad territorial -máximo signo de poder económico- era de difícil acceso, el diploma universitario parecía más próximo y de esta manera eran más asequibles tanto el logro de una legitimación simbólica como de un mayor progreso económico (Cfr. Chiroleu, 2000, p. 364). Como vemos, la apuesta de Greca en torno a la legitimación dentro de este contexto universitario es significativo.

\section{Un hombre de estudio al servicio del bien común: el urbanismo}

En su itinerario intelectual, el urbanismo fue entendido como una ciencia que concentra en sí una multiplicidad de disciplinas: "en el estudio de los problemas urbanos intervienen el arquitecto, el ingeniero, el sociólogo, el jurista, el historiador, el economista, el geógrafo, el artista, el psicólogo y vienen a ser urbanistas todos",

\footnotetext{
15 Sus contemporáneos sostenían que Greca, junto a Carmona Romay, profesor de Gobierno Municipal en la Universidad de La Habana, eran las figuras más destacadas del municipalismo latinoamericano (Delorenzo Neto, 1952; Carmona Romay, 1953).

16 Tanto la escritura de jurisprudencia como su labor parlamentaria demandarían realizar un estudio particular para generar una aproximación más cabal del itinerario intelectual de este escritor. Su inserción en el ámbito del derecho municipal como su performance en los cargos legislativos exigirían una revisión pormenorizada.
} 
apunta Greca (Cit. en Boasso, 2011, p. 99-101). Esta mirada multidisciplinaria, amplia e innovadora para el momento de su enunciación, no ejercía la primacía en los estudios urbanísticos que, en las primeras décadas del siglo veinte, seguían muy atados a la órbita de la ingeniería y la arquitectura. En la UNL, las cuestiones relativas a esta área comenzaron a tomar fuerza ligadas a tres figuras de fuste: el jurista más destacado de Rosario y fundador del Derecho administrativo en la Argentina y en buena parte de América, el ya citado Rafael Bielsa; el futuro intendente de Rosario y fundador del Colegio de abogados de Rosario José Lo Valvo ${ }^{17}$ (Rosario, 1895- Rosario, 1971) y Greca. Estos tres jurisconsultos coincidían en la importancia de impartir, desde la cátedra universitaria, conocimientos relativos a esta disciplina para la formación del abogado. La implicancia es algo más que una estrategia argumentativa, es la marca retórica de un núcleo de sólidas convicciones que resultaban innovadoras para el momento de su enunciación. Bielsa, el intelectual faro, era el centro de la Escuela del Litoral conformada por Greca, Dana Montaño y otros, en torno al estudio del derecho administrativo (Hernández, 2003, p. 118).

Esta apuesta multidisciplinar esgrimida resulta ciertamente novedosa. Más aun teniendo en cuenta que Greca desarrollaba estas cuestiones articulándolas dentro del espacio curricular Derecho Municipal, conjugando diversos planos de la función social de la universidad: sus prácticas transversalizan actores, funciones y saberes en el sentido que aportábamos en Antequera et al (2015)-, relacionando la docencia, la investigación, la gestión y la divulgación del conocimiento en clave de extensión universitaria. En otros términos, entendemos que Greca aunaba en sus propias prácticas universitarias estas funciones e intentaba articularlas con miras a implantar la disciplina en la universidad, contribuyendo a formar a los futuros abogados. Podríamos decir entonces que estaba fundando la disciplina, en el sentido más estricto del término. De algún modo, el campo de batalla de la disciplina, batalla por consolidar las ideas del urbanismo en ciernes y batalla por la legitimación del espacio de la disciplina, como vemos, también se libraba en el curriculum universitario.

Debemos recordar que, durante los primeros gobiernos radicales tanto la ciudad como la vivienda fueron una esfera más de intervención pública (Rigotti, 2001). Efectivamente, en este período el urbanismo fue ganando adeptos entre los intelectuales: Greca y el arquitecto e ingeniero Á. Guido, su amigo y propulsor de los planes urbanísticos de Rosario y de otras ciudades, compartieron estos desvelos por pensar una ciudad ordenada que, por otra parte, se estaba transformando en un artefacto sumamente complejo. A propósito, resulta digna de destacar una curiosidad: al correr del año 1957 y cumplirse un año del fallecimiento del sanjavierino, Guido le dedicó una pincelada necrológica en un periódico. La idea rectora es la vocación urbanística de Greca, destacada por Guido por sobre otras ${ }^{17}$ José Lo Valvo fue intendente de Rosario en el breve período: 06/04/1951 y 09/06/1952. También
se desempeñó como decano de Cs. Jurídicas y Soc. (UNL). 


\section{Alcides Greca (1889-1956), un hombre de letras y un hombre de estudio. Apuntes para la construcción de una biografía escrituraria}

facetas, quizás atravesado por sus propios intereses. En este homenaje póstumo, Guido se permite realizar una notable propuesta: sugiere designar con el nombre de Greca algún espacio verde e instalar un busto para dar "prestancia y dignidad espiritual" al lugar elegido. Nótese que el lugar propuesto por Guido es el mismísimo Monumento a la Bandera que él ideara y que tanto esfuerzo, contrariedades y tantos años de trabajo -casi tres décadas- le insumiera. Subyace en este "proyecto práctico y viable", según Guido, de homenaje de la ciudad a uno de sus hombres ilustres, una clara intención didáctica: "para que los jóvenes lo tomen a Greca como ejemplo" (s/d).

Más adelante, Guido apuntaba que los unía "una amistad sin fronteras" y proseguía: "nadie podrá olvidar su estirada y casi gigantesca figura desgarbada, siempre desbordante de simpatía -suerte de Quijote litoraleño- ya que bien sabemos sus amigos que detrás de ese tono burlón bien criollo por cierto, escondía un apasionado corazón romántico, uno de los más líricos de su generación".

En el año 1939, Greca publicó un libro bastante polémico titulado Problemas de urbanismo en la República Argentina, surgido de unas conferencias que dictó en Cuba (1938). Anclado en el campo de la política municipal, como expone en el prólogo, intentó establecer con este volumen una acción complementaria de su obra jurídica más importante y con mayor repercusión, Derecho y ciencia de la administración municipal, de 1937. Este fue su cometido declarado: por el perseverante trabajo en la cátedra universitaria y "en la observación diaria de las actividades de los municipios [...] Existen problemas urbanos argentinos, propios de nuestra organización económica y formación social, que reclaman soluciones inmediatas. Las que damos no pretendemos sean las únicas ni definitivas". Para más adelante agregar: "Otros hombres de estudio podrán aceptarlas o rechazarlas, pero de cualquier manera, entendemos que al abrir debate sobre cuestiones de trascendencia para la buena organización administrativa y eficaz acción de nuestras comunas, realizamos obras de bien público" (Greca, 1939, p. 5). Entendemos que estas líneas condensan también su querer ser hombre de estudio, de mirada honda sobre las problemáticas de su tiempo, aquellas que aquejaban al bien común.

Asimismo, hacia finales del año 1948 Alcides Greca fue invitado a Brasil por la Ordem dos Advogados do Brasil, para disertar e intercambiar ideas sobre derecho municipal y algunos problemas de urbanismo como por ejemplo, el proyecto del traslado de la futura capital brasileña y la creación de Brasilia. Fruto de estas conferencias (Fig. 2) y viajes, escribió dos libros: el relato de viajes Bahianos y bandeirantes (editándolo en 1950 en español y en 1955 en portugués, a modo de una separata de la revista Universidad y como publicación de la Municipalidad de Salvador, respectivamente) (Antequera, 2016) y Una nueva capital para la Nación Argentina, donde expuso que el mal que aquejaba a la Rep. Arg. era el centralismo de Bs. As que va en desmedro de las provincias.

Con miras a concluir este bosquejo, cabe agregar que en 1954, Greca se jubiló como profesor universitario. Se trasladó a la localidad de Oliveros, vecina a Rosario, donde a instancias de haber adquirido una chacra, se dedicó a cultivar su huerta y jardín. 


\section{María Florencia Antequera}

La mañana del lunes 16 de abril de 1956 falleció de pancreatitis en una cama del Hospital Italiano Garibaldi ${ }^{18}$.

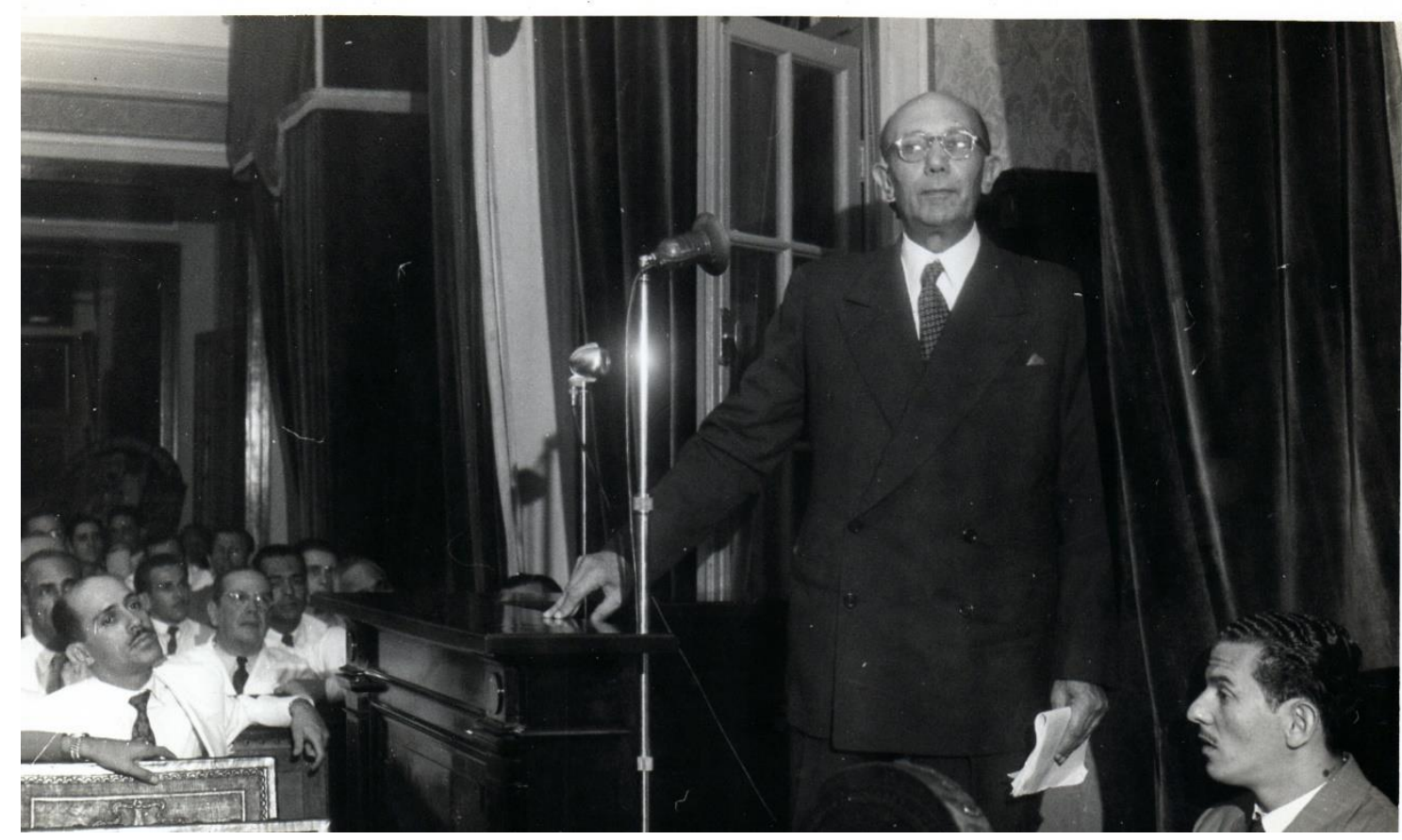

Fig. 2 Alcides Greca en plena conferencia organizada por la Orden dos advogados do Brasil. San Salvador de Bahía, noviembre de 1948. Foto: Gentileza Colección documental Familia Greca.

\section{Consideraciones finales}

Como vemos, su vida fue esencialmente tomar partido: tanto en la universidad, el periodismo, el urbanismo, la militancia política, la jurisprudencia, el cine y, por supuesto, la literatura. 0 mejor aún, en todos esos frentes pero por sobre todos, en la literatura, que de algún modo, los transversaliza en el deseo que aguijoneó todo su itinerario: ser un hombre de letras y un hombre de estudio. Este es el motor de su proyecto creador. Compromiso político, cultura letrada, pertenencia a la Universidad son ítems que se relacionan en su biografía y que delinean esta semblanza biográfica que quisimos trazar. Para finalizar, queremos incluir unas pinceladas biográficas, tomadas del prólogo que escribió Bielsa a la obra póstuma de Greca Régimen legal de la construcción (1956). Dice Bielsa de Greca:

un trabajador infatigable que solamente en el trabajo, en la tarea diurna, encontraba reposo. Y esa noble tarea es expresión de la verdadera vocación jurídica, que reveló a lo largo de su vida, aun en el período de su intensa actividad política en la legislatura de Santa Fe y en el Congreso Nacional. Esa actividad, unida a la de la cátedra y a la del periodismo, contribuye a definir o

18 El Litoral del 16 de abril de 1956. 


\section{Alcides Greca (1889-1956), un hombre de letras y un hombre de estudio. Apuntes para la construcción de una biografía escrituraria}

caracterizar la obra del maestro desaparecido. Cuando actuó en el periodismo hizo en él, en cuanto pudo, algo así como una prolongación de su cátedra.

En su juventud la vocación política lo llevó a la lucha en defensa de ideales y aspiraciones de vida y fue tan intensa su acción que llegó a ser popular en Santa Fe, su provincia natal. Con otros hombres de su generación, animados de un fervor cívico y ansias de cultura, emprendió una cruzada dirigida a la creación de la Universidad Nacional del Litoral como proyección mayor de la antigua Universidad de Santa Fe, cruzada que comenzó varios años antes de la reforma de 1918, lo que explica que bajo el signo de esta se estableciera la Universidad Nacional, en 1920. Fue entonces cuando conocí a este gran inquieto, pues él y yo fuimos nombrados profesores titulares.

Con miras a la aquilatada configuración de esta semblanza biográfica y con la finalidad de comprender más cabalmente su legado, que aún no ha sido suficientemente atendido, ponemos en consideración este material biográfico cotejado tanto en el Museo Histórico de la UNL como en el archivo personal que custodia la familia del escritor.

\section{Referencias bibliográficas}

\section{Fuentes}

Greca, A. (1912). Lepra (Panfleto de combate). Santa Fe: Éxito.

Greca, A. (1927). Viento norte. Novela del norte santafesino. Rosario: Inca.

Greca, A. (1929). La torre de los ingleses. Buenos Aires: Inca.

Greca, A. (1931). Cuentos del comité. Buenos Aires: Lux.

Greca, A. (1936). La pampa gringa. Novela del sud santafesino. Santiago de Chile: Ercilla.

Greca, A. (1941). En torno al hombre. Buenos Aires: Losada.

Greca, A. (1950). Bahianos y bandeirantes. Santa Fe: Universidad Nacional del Litoral.

Greca, A (1956). Régimen legal de la construcción. Buenos Aires: Víctor de Zavalía.

La pura verdad, San Javier, 1911. s/d

Democracia, Santa Fe, 24 de julio de 1929 


\section{María Florencia Antequera}

\section{Textos críticos}

Antequera, M. F. (2017). Alcides Greca, viajero. Apuntes sobre el diálogo en La torre de los ingleses (1929) y materiales pertenecientes a su archivo privado. Anuario del Centro de Estudios Históricos Prof. Carlos S. A. Segreti. (17), 22-39.

Antequera, M. F. (2018). El relato de viajes en la obra de Alcides Greca como formación de una subjetividad moderna en el campo intelectual argentino. Tesis doctoral. Universidad Nacional de Cuyo, Mendoza.

Antequera, M. F. (2019). Alcides Greca. El viaje de la escritura y la escritura del viaje. Mendoza: EdiFFyL, Universidad Nacional de Cuyo. (En prensa)

Bielsa, R. (1956). Prólogo. En A. Greca: Régimen legal de la construcción. Buenos Aires: Víctor de Zavalía.

Boasso, P. (2011). Juristas rosarinos del siglo XX. 1900-1980. Buenos Aires: Dunken. Bourdieu, P. (2008). Capital cultural, escuela y espacio social. Buenos Aires: Siglo XXI.

Cattaruzza, Alejandro y Eujanían, Alejandro (2003). Políticas de la historia. Argentina 1860-1960. Buenos Aires: Alianza.

Greca, D. (2014) De la historia en el cine al cine en la historia: potencialidades como documento del film El último malón. Revista digital de la Escuela de Historia UNR, $6(10)$.

Greca, D. y V. (2013). Un abordaje interdisciplinar de un relato cinematográfico: aproximación a la película El último malón (1917) desde la Antropología y la Historia. Claroscuro, Revista del Centro de Estudios sobre Diversidad Cultural de la FHumyAr UNR, 11.

Hernández, A. (2003) Derecho municipal. México: UNAM.

Ferrary, Álvaro (1999). La mirada intelectual de ver las cosas: exploración abierta a la figura del intelectual contemporáneo. Memoria y Civilización, 2, 291-313.

Goloboff, M. (2014). Leer Cortázar. Buenos Aires: Continente.

Gramuglio, M. T. (1992). La construcción de la imagen" en Tizón, H.; Rabanal, R. y Gramuglio, M. T. La escritura argentina. Santa Fe: Universidad Nacional del Litoral.

Macor, D. y Piazzesi, S. (2010). El Radicalismo y la política santafesina en la Argentina de la primera república. Estudios, 23. Recuperado de: http://www.scielo.org.ar/scielo.php?script=sci_arttext\&pid=S1852156820100001 00006\&lng=es\&nrm=iso 
Alcides Greca (1889-1956), un hombre de letras y un hombre de estudio. Apuntes para la construcción de una biografía escrituraria

Persello, A. (2007). Historia del Radicalismo. Buenos Aires: Edhasa.

Piazzesi, S. y Bacolla, S. (2015). Tradiciones reformistas y 'cuestión universitaria' en espacios provinciales. Santa Fe en los inicios del siglo XX, Actas Digitales XXXIV Encuentro de Geohistoria Regional, Instituto de Investigaciones Geohistóricas, Resistencia. Recuperado de: http://www.iighiconicet.gob.ar/wpcontent/uploads/2015/10/XXXIV-EGHR.pdf

Romano, E. (1991). Literatura/cine argentinos sobre la(s) fontera(s). Buenos Aires: Catálogos.

Santa Cruz, I. (1981). Los Cuentos del Comité de Alcides Greca. En AAVV. Narrativa argentina del Litoral. Rosario: Cuadernos Aletheia del Grupo de estudios semánticos.

Recibido: 30/01/2020

Evaluado: $15 / 03 / 2020$

Versión Final: 01/04/2020 